\title{
La crítica y la educación médica: hacia un conocimiento liberador. Parte I
}

\author{
Leonardo Viniegra-Velázquez* \\ Unidad de Investigación en Medicina Basada en Evidencias, Hospital Infantil de México Federico Gómez, Ciudad de México, México
}

\begin{abstract}
Resumen
Como marco intelectivo e interpretativo de este trabajo se propone y argumenta el diagnóstico del momento actual como colapso civilizatorio, provocado por la dominancia de los intereses de lucro sin límites, que ha sido posible por la insensibilidad y la permisividad mayoritarias de la población ante una degradación social y ecosistémica extrema. Detrás de tal «anestesia» está la dominación de conciencias y cuerpos basada en una educación que reproduce las ideas y las prácticas prevalentes en cada espacio social y perpetúa los rasgos degradantes: individualismo, especialización excluyente, pasividad, competitividad, consumismo y vulnerabilidad a la manipulación mediática. En esta primera parte, la crítica de la esfera educativa de la educación médica significó diferenciar y contrastar dos tipos de educación radicalmente distintos. El primero es la educación pasiva, de vigencia universal que subyace a la degradación, cuyo núcleo es la idea de conocimiento equiparable a un aprendizaje memorístico y acumulativo de información heterónoma y desvinculada, y por una pedagogía implícita centrada en estimular y facilitar el consumo y la asimilación acrítica de las verdades establecidas. El segundo es la educación participativa, una propuesta de superación de la pasiva, en la que el conocimiento es elaboración y reelaboración propia de los educandos con la mediación imprescindible de la crítica profunda, que construyen y reconstruyen versiones propias de sí mismos y su contexto; su pedagogía se resume en contagiar entusiasmo por entender quiénes somos y dónde estamos, y procurar ambientes propicios para la crítica y la elaboración de un conocimiento penetrante y liberador, que ha mostrado su factibilidad en situaciones concretas.
\end{abstract}

Palabras clave: Colapso civilizatorio. Rasgos degradantes. Crítica. Conocimiento. Educación médica. Educación pasiva. Educación participativa.

\section{Critique and medical education: towards liberating knowledge. Part I}

\section{Abstract}

This essay defines the current moment as a civilizatory collapse, consequence of the dominance of limitless profit interests, which has been possible due to the insensitivity and permissiveness of most of the population in the face of extreme social and ecosystemic degradations. In the background of such "anesthesia" there is the predominant education and its key role in the reproduction of prevalent social ideas and practices and in the perpetuation of degrading traits: individualism, exclusionary specialization, passivity, competitiveness, consumerism and vulnerability to media manipulation. With this intellective and interpretive framework, the concept of deep and creative critique was updated in order to deepen the critique of

\section{Correspondencia:}

*Leonardo Viniegra-Velázquez

E-mail: leonardo.viniegra@gmail.com
Disponible en internet: 01-11-2018 Bol Med Hosp Infant Mex. 2018;75:327-337

www.bmhim.com

1665-1146/C 2018. Hospital Infantil de México Federico Gómez, impreso por Permanyer México SA de CV, todos los derechos reservados. 
medical education, allowing for the differentiation and contrast of two radically different types of education. Firstly, the passive education, reproductive of the degrading traits of universal validity, whose core is the idea of knowledge comparable to a cumulative rote learning of heteronomous and unrelated information, and by an implicit pedagogy focused on facilitating the consumption and uncritical assimilation of established truths. Secondly, the participatory education (proposal to overcome the passive), where knowledge is the elaboration and re-elaboration of students with the essential mediation of critique. The students construct and reconstruct their own versions of themselves and their context; the implicit pedagogy is condensed in infecting enthusiasm to understand who we are and where we are, and procure conducive environments for critique and the elaboration of a progressively penetrating and liberating knowledge that has shown its feasibility in specific situations.

Key words: Civilizational collapse. Degrading traits. Critique. Knowledge. Medical education. Passive education. Participatory education.

La docencia realmente fecunda principia cuando "contagia entusiasmo" por entender quiénes somos y dónde estamos.

El autor

\section{Introducción}

Para los saberes ortodoxos y convencionales, la institución escolar ha sido y es «la forjadora de las fuerzas liberadoras y de superación de la condición humana». Sin embargo, la crítica del quehacer de la escuela revela que tal afirmación es una idealización, una ilusión, dado su papel histórico ineludible (que escapa a la conciencia de los actores) en la reproducción de las ideas y prácticas, los usos y costumbres predominantes en los diversos campos del quehacer social; predominio que no obedece a una supuesta superioridad sobre otras, sino a su sintonía, directa o indirecta, con los intereses dominantes del momento histórico ${ }^{1}$. Esto explica que, en nuestro tiempo - ante la dominancia de los intereses de lucro sin límite que ha degradado la civilización hasta su colapso al aniquilar los anhelos de libertad, igualdad, justicia y autodeterminación de los pueblos, arrasar los valores propios de convivencias respetuosas, fraternas y solidarias, y devastar el ecosistema planetario ${ }^{1}$, la población con el mayor nivel de escolarización de la historia haya permanecido mayormente insensible, indiferente o permisiva con la degradación.

Tal papel escolar forzoso no es óbice para perseverar en la búsqueda de un mundo hospitalario que precisa una educación liberadora basada en la crítica, cuya premisa es concienciar quiénes somos: una humanidad de culturas diversas, etnocéntricas, belicosas, opresoras y oprimidas, que crece sin control, agota los recursos naturales, contamina y diezma la biósfera, "anestesiada» al colapso; y dónde estamos: tiempos aciagos de desigualdad extrema, vileza, despojo, precariedad, exclusión, inseguridad, violencia y terror, donde la degradación que hemos provocado al ecosistema ha rebasado el umbral de reversibilidad, ha encendido alarmas y ha movilizado numerosos contingentes, y prefigura un mundo inhóspito para las generaciones futuras y de extinciones aceleradas de buena parte de las grandes especies silvestres.

Precisar el momento histórico, el tipo de educación que prevalece a escala global particularizando en la educación médica, identificar los saberes predominantes tanto en lo educativo como en lo médico que forman profesionales mayormente indiferentes a la degradación, y argumentar alternativas tendientes a la superación del proceso formativo de este personal de salud, son los motivos de este trabajo.

\section{El momento actual y la educación}

Si bien el imperio de los intereses de lucro es de larga data, es a partir de los 80 cuando el capital encabezado por el especulativo- acentúa su dominación sobre el trabajo: elude, debilita o anula regulaciones, derechos laborales, prestaciones sociales y organizaciones gremiales ${ }^{2,3}$. También intensifica la depredación de la naturaleza-mercancía hasta comprometer los soportes de la vida planetaria. Su difusión universal por todos los medios, incluida la guerra («la diplomacia de los misiles") como motor irresistible de una globalización económica y política acorde a sus intereses de creciente rentabilidad, expansión y concentración, nos ha arrastrado al colapso civilizatorio. Este, por supuesto, es maquillado o negado por los medios masivos de comunicación occidentales al servicio de la dominación, que desinforman, censuran, tergiversan sucesos, atacan o desacreditan gobiernos u organizaciones «insumisas», oscurecen las raíces de los problemas que padecemos o encubren la conexión 
de los intereses dominantes con las atrocidades y catástrofes que se multiplicana. Estas «realidades fabricadas" controlan conciencias y cuerpos de inermes consumidores que, insensibilizados al momento actual, permanecen mayormente ajenos, indiferentes, acomodaticios o cómplices de la dominación de los intereses de lucro sin límite con funestas consecuencias ${ }^{4}$. Los aparatos de manipulación y persuasión a escala global son decisivos en la conformación de subjetividades desinformadas que interpretan los aconteceres a conveniencia de la dominación sin concienciar la degradación omnímoda en curso. Esto revela que la educación universal, a pesar de su gran diversificación, de sucesiones de corrientes de pensamiento y de «revoluciones educativas", de multiplicidad de modalidades, de métodos pedagógicos, de propósitos, niveles o grados de especialización, ha sido desplazada y suplantada en su papel formativo, y que, ante el mayor desafío de nuestra historia, que es el colapso civilizatorio y ambiental que amenaza gravemente la viabilidad de la vida en el planeta y nuestra permanencia como especie, se muestre inconmovible, ajena, tibia, ciega o encubridora, y por tanto irrelevante en la consecución efectiva de un mejor mundo para las mayorías.

Tal situación histórica también expresa los condicionamientos de los actores: reformadores, directivos, profesorado o alumnado, víctimas propiciatorias del control por los aparatos de manipulación y persuasión globales, portadores de usos y costumbres que operan como "agentes encubiertos» de la dominación en este campo. Así, se asume que estos «templos del saber» requieren sustraerse del «mundanal ruido" y centrarse en lo suyo. Con respecto a los planes y programas, se da preferencia a ciertos diseños curriculares, métodos pedagógicos, disciplinas, materias o prácticas por su procedencia "del mundo desarrollado», aduciendo actualidad, moda, vanguardia, progreso, utilidad, pragmatismo o superioridad sobre otras. En contraste, se

a Las redes sociales vía internet (cuyo origen, centro de gestión y control son los EE.UU.), que se piensan como "flujos democratizadores de la información", son instrumentos clave del sistema de dominación: espionaje que anula la privacidad y hasta la intimidad para depurar perfiles, disidencias, inconformidades, oposiciones o rebeldías. Son una vía de inusitada penetración para desinformar, inducir prejuicios, filias, fobias, temores paralizantes, ilusiones vanas y consumismo compulsivo, o desacreditar gobiernos, etnias, organizaciones, grupos o personas «indeseables», "enemigos de la civilización»; dilución de mensajes y opiniones esclarecedoras y de fondo en océanos de banalidades o falsedades; «secuestro virtual» de los usuarios que se aíslan e insensibilizan a la degradación y la catástrofe que padecemos. rechaza o elimina lo anticuado, lo poco útil, lo impráctico, lo teorizante, lo especulativo, lo complejo, lo heterodoxo o lo "subversivo", destacando la subestimación o exclusión del pensamiento teórico, del pensamiento filosófico (con sus diversas disciplinas y variantes) o del pensamiento crítico, que sacude la quietud y la aquiescencia y cuestiona las verdades establecidas. Esos condicionantes también explican por qué, a lo largo de la historia, diversos esfuerzos reformadores por encauzar la educación en un derrotero liberador se quedaron en ciernes, en el discurso, resultaron inviables o fallidos, o sufrieron tergiversación, depuración de lo «espinoso" o cambios regresivos.

\section{El ethos de la civilización actual y la educación}

La educación que prevalece en las sociedades actuales y que parece "coexistir pacíficamente" con el colapso civilizatorio y la devastación ambiental, en su papel reproductor de las ideas y las prácticas predominantes de la cultura de que se trate, forma legiones de especialistas explotables por un mercado de trabajo muy diversificado y tecnificado, cada vez más restrictivo, escaso e inseguro, pero se abstiene — con raras excepciones - de despertar el entusiasmo de los educandos por entender quiénes somos y dónde estamos, fundamento del conocimiento realmente liberador. En ese afán por convertirse en fábrica rentable de «mercancías» competitivas, dóciles y apetecibles, la escuela se centra en reproducir "la fuerza de trabajo actualizada» que las empresas requieren, y se aleja cada vez más del ideal de «forjar las fuerzas liberadoras y de superación de la condición humana». De ahí su irrelevancia para atenuar, contrarrestar o neutralizar las consecuencias funestas de la dominancia de los intereses de lucro sin límite. En el mismo sentido, el personal escolar, al profesar las ideas y prácticas predominantes, contribuye con su proceder a perpetuar el ethos de una civilización en fase de agotamiento. Los rasgos más destacables son los siguientes ${ }^{5}$ :

- Individualismo, que supone proyectos vitales de "cada quien lo suyo y sálvese quien pueda», insensible y distante de los intereses colectivos y sus reivindicaciones, ajeno a acontecimientos que ocurren más allá del círculo cercano por más que a todos atañan, y sean atentados contra la dignidad más elemental. En el mundo individualista, «la responsabilidad colectiva por los males de la sociedad no existe".

- Especialización reduccionista y excluyente, forma predominante de la división del trabajo, en la que el 
especialista, con una visión fragmentaria e inconexa del mundo, no capta la interrelación de los acontecimientos que lo sacuden y afectan. Además, muestra desinterés por conocer el contexto histórico y social que le tocó vivir, genera distancia o aversión al pensamiento complejo e integrador («lo importante es estar al tanto del propio ámbito de actividad; lo demás es harina de otro costal»), y vive sumergido en un mundo individualista, oscuro, caótico e inseguro.

- Pasividad ante los excesos y abusos del poder que aplasta los derechos, cuya raíz son las graves limitaciones cognoscitivas propias de la especialización reduccionista y excluyente, a lo que se agregan las actitudes predominantes de impotencia o dejación ante las adversidades, que han sido interiorizadas y se manifiestan en conformismo, fatalismo e inacción.

- Competitividad propia de un mercado de trabajo restrictivo, injusto, precario e implacable, que fomenta relaciones de rivalidad, desconfianza o antagonismo (no de solidaridad), que exacerban la voluntad de dominio con sus secuelas: desigualdad, abuso, sometimiento y exclusión.

- Consumismo real o imaginario de toda clase de objetos materiales y simbólicos para satisfacer deseos y obsesiones, o desfogar angustias e insatisfacciones, que sostiene una economía que profundiza las desigualdades, agota los recursos naturales y devasta el planeta. Este consumismo controla conciencias y cuerpos al suplantar y adulterar los vínculos intersubjetivos, al inducir deseos irrefrenables por medio de una publicidad avasallante y favorecer conductas evasivas y adictivas de todo tipo.

- Alta vulnerabilidad a la manipulación mediática con respecto a multiplicidad de asuntos que se desconocen o escapan al entendimiento, enraizada en el individualismo y la especialización excluyente.

Tales rasgos, que "se respiran en la atmósfera global» reproducidos por la escuela y que subyacen a la insensibilidad o complicidad con la degradación, se designan rasgos degradantes dada su permisividad con el ánimo desaforado de lucro que encuentra escasas y dispersas resistencias en su camino destructivo. $\mathrm{Ni}$ que decir tiene que estos rasgos exhiben gran variabilidad, y algunos están atenuados o ausentes en multitud de organizaciones; particularmente, en un buen número de pueblos y culturas originarias de la geografía planetaria que representan, en muchos casos, la reserva moral y convivencial de nuestra autodestructiva especie, víctimas sin tregua de exclusión, despojo o violencia si se oponen al progreso... de los buenos negocios.

\section{La educación pasiva}

Para captar por qué la educación es mayormente reproductora — por acción u omisión- de los rasgos degradantes es preciso retrotraerse a la división del trabajo social cuando se disociaron producción y uso del conocimiento, y la escuela asumió el papel de resguardarlo, atesorarlo, ordenarlo y transmitirlo. Desde tiempos remotos, la escuela debió equiparar información con conocimiento y favorecer actitudes aquiescentes, acumulativas y acríticas en los educandos con «las verdades establecidas». Así, prevaleció la idea de conocimiento como consumo, acumulación y retención de información, y languideció la de participación como generación de ideas, opiniones o iniciativas propias. De ahí el denominarla educación pasiva, desarrollada de manera extensa y pormenorizada en otros lugares $^{6,7}$. Ahora, al referir los caracteres más destacables de la educación pasiva, cabe subrayar que no se encuentran en estado puro, sino en forma de predominios. En situaciones concretas y dependiendo del nivel educativo, estas características muestran infinidad de variantes, matices e intensidades:

- Un currículo fragmentado en multitud de temas y materias desvinculadas, donde se disocian teoría y práctica, favorece en los educandos la incomprensión, el desinterés y hasta el recelo del pensamiento complejo e integrador, lo que "germina» en una visión del mundo fragmentaria e inconexa que, a la larga, oscurece la interdependencia de los acontecimientos que los sacuden y afectan, cuya resultante en los niveles superiores es la especialización reduccionista y excluyente.

- Los temas de estudio (particularmente en el nivel básico) suelen carecer de sentido para lo que más interesa, conmueve, preocupa, despierta curiosidad, atrae o entusiasma a los educandos por su momento etario (experiencia vital), condicionando un aprendizaje insulso y fugaz que no deja huella, que "vacuna" contra el hábito de estudio 0 , peor aún, refuerza la idea de que en la educación formal no se aprende «lo importante para la vida» (raíz de la deserción escolar y la autoexclusión).

- Desalienta o reprime el deseo por el conocimiento (raíz de la pasividad ante los abusos del poder), representado en el imaginario de los educandos por información mayormente desvinculada y carente de sentido que deben recordar so pena de menosprecio o exclusión.

- Al reducir el acto cognitivo al consumo, la acumulación y el recuerdo de información, y propiciar la aceptación 
tácita y acrítica de las verdades establecidas, refuerza la pasividad de los educandos ante el conocimiento, adormece las potencialidades cognoscitivas y críticas, y los hace vulnerables a la manipulación que desinforma, induce creencias, prejuicios, filias, fobias o temores paralizantes.

- El sistema escolar en su organización, métodos pedagógicos y didácticos, prioridades temáticas, formas de trabajo de alumnos, tareas o exigencias de rendimiento, equipara aprendizaje con recuerdo de información -a mayor recuerdo, mayor éxito escolar (que supone mayor consumo) - y refuerza la competencia entre educandos (por alcanzar distinciones, reconocimiento o evitar la exclusión) y el consumismo que apuntala el modelo económico que colapsa la civilización.

- La evaluación, medio de control, clasificación, censura o exclusión de alumnos, lejos de fomentar la crítica constructiva y la autocrítica (camino insustituible de superación), suscita sentimientos y actitudes negativas o de rechazo, que la desvirtúan en el papel que debería cumplir: estimular el aprendizaje.

- La idea de progreso escolar basada en lo instrumental: la disponibilidad y el uso de las tecnologías de la información y la comunicación potencia el consumismo y la dependencia de tecnologías fetichizadas.

- Los egresados de la escuela reproducen y amplifican los rasgos degradantes que caracterizan a las sociedades actuales, con proyectos vitales de "cada quien lo suyo y sálvese quien pueda», que acentúan la desigualdad, la marginación, la injusticia, la exclusión, la opresión, la violencia y la inseguridad, y avanza la devastación planetaria.

Estos caracteres de la educación pasiva son extensivos, mutatis mutandis, a la educación médica ${ }^{4}$, insistiendo en que, en situaciones concretas, no se encuentran ni en estado puro ni en su totalidad, sino en forma de predominios. Al respecto, es obvio que numerosos egresados se distancian de tales caracteres, pero por razones «extracurriculares" y frecuentemente "a pesar de la escuela». La moda actual de las competencias profesionales no representa un cambio de fondo; se trata más bien de actualizaciones y adecuaciones del currículo médico a las necesidades del mercado que deja intocados los rasgos degradantes y donde la crítica es un aderezo del discurso con escasas posibilidades de ejercerse y profundizarse $\mathrm{e}^{8-12}$.

\section{La crítica y el conocimiento}

Los esbozos del pensamiento crítico aparecen con los primeros grupos humanos en los actos reflexivos de su experiencia vital en la preservación de su integridad y vitalidad, la consecución de alimento, la convivencia comunitaria, la crianza, la elaboración de herramientas 0 al enfrentar fenómenos naturales amenazantes o peligrosos. La reflexión es, en principio, concienciar aconteceres, y en particular los actos propios y de grupo respecto a sus fines. Cuando la reflexión permitió discernir y comparar entre modos de hacer las cosas según los logros, fue posible el perfeccionamiento de acciones cada vez más apropiadas o efectivas para lo buscado. Así, surgieron los basamentos de la crítica. Sin embargo, al aparecer los dogmas - las religiones primitivas y los monoteísmos que las sucedieron para dar sentido a la existencia, confortar ante la inexorabilidad de la muerte o conjurar adversidades y catástrofes- la crítica debió restringirse al ámbito instrumental, vedándosele las ideas existenciales, lo que ha permanecido, sin grandes cambios, hasta nuestros días.

\section{La crítica profunda y creativa}

La crítica sobreviviente de innumerables vicisitudes históricas, a pesar de sus puntos ciegos y graves limitaciones, suscita recelo o es blanco de intimidación de los centros de poder, y es soslayada o malentendida en las sociedades mediatizadas; de ahí los riesgos de rehabilitarla como medio cognoscitivo imprescindible y develar sus alcances potenciales. En esta búsqueda, la idea de crítica se ha modificado desde sus versiones iniciales ${ }^{13}$. Así, otras facetas de la crítica se fueron clarificando y especificando (jla crítica de la crítica!) hasta su formulación actual como la lógica de pensamiento metódico del proceso de cognición, que pone el acento en dos aspectos del proceso (ignorados, soslayados o minimizados por otras corrientes). El primero, afín a la tradición filosófica, es la inclinación a ponerlo todo en cuestión (supuestos implícitos, ideas, hechos, usos y costumbres), a dudar de lo "comprobado o definitivo", a intentar llegar a la raíz de lo que parece natural y evidente. El segundo incita el potencial creativo del sujeto, confiriendo a la crítica verdadero sentido, predisposición a idear y proponer formas de pensar, escudriñar y actuar, que aspiran a superar lo establecido respecto a los objetos de conocimiento en cuestión; de ahí el denominarla crítica profunda y creativa para distinguirla de acepciones comunes, como juicios superficiales en pro $o$ en contra, 0 argumentaciones tendenciosas para legitimar, censurar o descalificar.

El primer aspecto de la crítica profunda y creativa que representa el sano escepticismo en la búsqueda 
del conocimiento tiene particular relevancia en estos tiempos de guerra mediática (entre otras) contra todo lo que resista, estorbe o se oponga al dominio de los intereses del capital especulativo y de las grandes corporaciones, que persuade, desinforma y espía, fabrica «realidades paralelas» que embaucan y controlan mentes y cuerpos, domesticándolos e insensibilizándolos a la degradación en curso, lo que, aunado a las ideas y prácticas predominantes en los distintos ámbitos del trabajo social —que deben su predominio a una especie de sintonía, directa 0 indirecta, con los intereses dominantes- operan como "agentes de la dominación» por esos intereses que nos precipitan al colapso civilizatorio que devasta el ecosistema planetario. Esto significa que ejercer la crítica para develar esos agentes y proponer alternativas al orden impuesto es, ahora, un imperativo de supervivencia.

El sentido de la crítica profunda y creativa es facilitar elaboraciones de un conocimiento cada vez más penetrante del sí mismo que se extiende a la humanidad (quiénes somos), y del contexto extensivo al mundo que habitamos (dónde estamos). Su posibilidad radica en las potencialidades cognoscitivas inherentes a la condición humana — negadas, ignoradas, reprimidas o inhibidas secularmente -en tanto, primordios de cognición pueden ser avivados por esta lógica para convertirse en potencias, que al desarrollarse y progresar en su poder cuestionador y generativo pueden liberar las mentes de las ideas y prejuicios que las constriñen y someten, para que las impulse en la búsqueda de otro mundo posible a contrapelo de la degradación.

La crítica se perfecciona a través de las potencias cognoscitivas que anima. Lo primario para su ejercicio es que surja un genuino interés cognitivo por ciertos objetos debido a su significado afectivo y trascendencia vital, como el sí mismo y el contexto percibido. Este interés, por efecto de la crítica, toma forma de inclinación y de un carácter cuestionador y propositivo que posibilita el dominio - siempre inacabado- de las habilidades cognoscitivas implicadas en la penetración cognitiva del objeto, para actuar en consecuencia (en general, solo se puede dominar y destacar en profesiones, oficios o aficiones que despiertan vivo interés). Se comprende, así, que en la educación pasiva - que prioriza el consumo y la acumulación de información ajena al sujeto y desalienta el deseo por el conocimiento como elaboración propia- prevalecen circunstancias en las que la crítica es una quimera y su perfeccionamiento es ilusorio.

A continuación, los atributos más destacables de la crítica profunda y creativa. Se trata de puntos de llegada no definitivos en la búsqueda y la caracterización de esta teoría de la crítica, cuyos inicios se remontan a dos décadas ${ }^{13}$. Por tanto, no se proponen aquí como punto de partida u objetivos de corto plazo de quienes emprenden su aventura cognitiva, sino para precisar lo distintivo de la crítica profunda y creativa respecto de otras ideas. Operan como indicador de su presencia y desarrollo efectivos al acometer asuntos de interés, o como punto cardinal que oriente su profundización en la construcción del conocimiento.

- Inclinación cuestionadora del conocimiento establecido que distingue dos objetos:

a) Las lógicas profundas subyacentes que condicionan las formas predominantes de pensar, idear, percibir, actuar u organizarse (antropocentrismo, etnocentrismo, colonialismo, reduccionismo o empirismo), y las ideas y prácticas prevalentes en los diversos ámbitos del trabajo social.

b) Las versiones tendenciosas y falaces de los aconteceres del mundo que difunden los aparatos mediáticos de la dominación.

- Avidez ponderada por formas de pensar, de actuar, de ideas, puntos de vista o informaciones divergentes de la ortodoxia, que al permitir contrastar o contrapesar lo predominante favorecen perspectivas e interpretaciones más aproximativas a la realidad de los sucesos. Al ampliar el horizonte reflexivo, acrecientan la materia prima para elaborar alternativas que busquen superar lo establecido.

- Dos componentes interdependientes e indisociables con sus respectivos objetos cognitivos: la autocrítica, vía preferente de conocimiento del sí mismo (quiénes somos), y la heterocrítica, orientada al contexto (dónde estamos).

- Predisposición a idear y proponer formas de pensar e interactuar alternativas a lo establecido respecto a los objetos cognitivos en cuestión.

- Actitudes colaborativas derivadas de la evidencia de superioridad cognoscitiva de los proyectos colectivos.

- Fortaleza al perseverar - a pesar de la censura o el rechazo de los centros de poder-, derivada de la afectividad depositada en ese objeto simbólico deseable, valioso y provechoso: el conocimiento del sí mismo y del contexto.

- Visión epistemológica que prima las ideas sobre los hechos, y lo integrador sobre lo fragmentario, como objetos de crítica (al contrario del empirismo reduccionista), y favorece un conocimiento transdisciplinario del sí mismo y del contexto. 
- Volición deliberativa al emprender, persistir, virar, desistir o reiniciar proyectos.

- Lógica, que organiza e integra las diversas habilidades cognoscitivas propias de lo siguiente:

a)La introspección: concienciar, reconocer, discernir, inferir, cuestionar, deliberar, idear.

b) La esfera de las ideas: comprender, analizar, reconocer, deducir, inducir, sintetizar, interpretar, confrontar, enjuiciar, integrar, jerarquizar, teorizar.

c) El mundo fáctico: definir el problema, las hipótesis y las aproximaciones; elegir modelos probatorios y de análisis de datos, los marcos interpretativos de los hallazgos o los alcances y las limitaciones de los estudios, donde la crítica de lo propio o lo ajeno implica deliberar y decidir con base en lo que se juzga más apropiado, relevante, suficiente, pertinente, fuerte, heurístico, factible o revelador.

d)La esfera de la práctica: construir montajes de observación apropiados, registrar hallazgos, elaborar artículos de investigaciones factuales o reflexiones, y ensayos sobre problemas, puntos de vista o teorías, o revisiones críticas de ellos.

e) El ámbito colectivo: comunicar, escuchar, dialogar, argumentar, debatir, controvertir, proponer, persuadir, incentivar, concertar o cooperar.

Se entiende de lo anterior que no hay cosas críticas: una teoría, una pedagogía o una obra de arte (que pueden construirse por medio de la crítica, pero no ser críticas per se). En cambio, sí puede haber conciencia, actitud o pensamiento crítico. La crítica profunda y creativa, como lógica de la cognición vigorizada por la afectividad, confiere penetración, versatilidad y fuerza creativa a las potencias cognoscitivas del sujeto, que es capaz de elaborar y reelaborar versiones aproximativas e inacabadas del sí mismo, cuyo horizonte es la condición humana, y del contexto, en último término, el mundo que habitamos. Cuando el conocer es fruto de las potencias cognoscitivas animadas por la crítica, se trata de una elaboración propia cuyo punto de partida obligado es la reflexión de la experiencia vital: las vivencias de interacción con objetos de gran significado (personas, cosas o sucesos) que conmueven, preocupan, gratifican, disgustan, atraen, repugnan, entusiasman o atemorizan. La inclinación a reflexionar la experiencia vital aparece cuando alguien significativo avezado a ello logra contagiar entusiasmo por entenderla como reveladora del sí mismo y del contexto, y puerta de entrada al conocimiento de uno y otro. Tal afectividad intensa y favorable surge cuando las potencias cognoscitivas, al elaborar el propio conocimiento, esclarecen dudas, conflictos o situaciones problemáticas, aportan claridad en el qué hacer o cómo hacerlo, suscitando estados anímicos de vivo interés, gratificantes o de sosiego que se condensan en entusiasmo por la elaboración. Lo anterior es extraño a la idea de conocimiento implícito en la educación pasiva: consumo y acumulación de información ajena, sin sentido para la experiencia vital, de presencia fugaz, que no deja huella afectiva favorable, sino vivencias superficiales o desagradables (sanciones por el olvido de datos en la evaluación).

\section{El conocimiento penetrante y liberador}

Después de especificar la versión actual de la teoría de la crítica profunda y creativa, cabe referirse al proceso de cognición a que da lugar como expresión de las potencias cognoscitivas animadas por la crítica: el conocimiento penetrante y liberador, que permite a los educandos ahondar en quiénes somos, dónde estamos y qué hacer en consecuencia. Sus atributos distintivos y alcances destacables son los siguientes:

- Proceso de cognición que, al vincular afectividad favorable e intelecto, suscita pasión, la fuerza vital de todo emprendimiento cognoscitivo perseverante $y$ fructífero.

- Elaboración de puntos de vista propios en el plano individual y en el colectivo con el intercambio y la colaboración sinérgica de los participantes.

- Progresión ascendente de esclarecimiento y poder liberador que implica lo siguiente:

a) Develar las lógicas subyacentes al proceso de cognición que lo bloquean, inhiben, restringen 0 desvirtúan.

b)Desarrollo de perspectivas transdisciplinarias de aproximación a los problemas cognitivos, más allá de los límites arbitrarios y ficticios entre disciplinas erigidos por la especialización excluyente del trabajo social. Se basan en la complejidad que deriva en visiones integradoras del sí mismo y del contexto, de la interdependencia de objetos y acontecimientos que sacuden la conciencia colectiva donde encuentre inteligibilidad el caos aparente del movimiento social, y representan contextos de interpretación y valoración en el momento de observar, experimentar, valorar, decidir o emprender.

c) Penetración del sí mismo, como miembro peculiar de una humanidad etnocéntrica, belicosa y destructiva (quiénes somos), y del contexto, como representación mínima de un mundo en tiempos 
aciagos de desigualdad, injusticia y violencia con un ecosistema devastado (dónde estamos).

d) Responsabilidad indeclinable (lo moral, cima del conocimiento penetrante) por el cuidado de la vida en todas sus manifestaciones y del ecosistema planetario.

e)Propuestas de superación de lo establecido o acostumbrado respecto al pensar, decir, actuar, investigar $u$ organizarse a contrapelo de la degradación, que lleva a emprender proyectos vitales altruistas y colectivos de lucha inacabable por un mundo propicio para la dignificación de la vida humana y planetaria (qué hacer).

\section{Crítica y educación médica}

Ahora, después de precisar la crítica profunda y creativa, y el conocimiento penetrante y liberador, que es consecuencia de su ejercicio, y argumentar acerca de su papel insustituible en la formación de colectivos iné-ditos capaces de develar quiénes somos, dónde estamos y qué hacer en consecuencia, se analizan sus implicaciones y significado para la educación médica. En primer término, respecto de la esfera educativa formal. Para la segunda parte, se deja lo relativo a las ideas y prácticas predominantes en el quehacer médico, que es el otro eje formativo de estos profesionales.

El primer paso en la crítica de las ideas y prácticas de la educación prevalente (incluida la educación médica) consistió en caracterizar la educación pasiva. Ahora prosigue al revelar que su predominio no es síntoma de superioridad, sino de sintonía con los intereses dominantes que adopta diversas formas:

- Una deriva de la privatización que sumerge a las instituciones educativas en las leyes del mercado, con la exigencia de constituirse en negocios de alta rentabilidad que convierte en mercancía la propia educación (no en un derecho humano) con la producción en serie de bienes animados apetecibles para un mercado de trabajo restrictivo y abusivo. Es decir, personal competente y versátil (en la operación de tecnologías), productivo, dócil, individualista, conformista e intercambiable. Aquí, la sintonía consiste en representar y afianzar los intereses dominantes.

- Otra se debe a la intromisión abierta, directa y creciente de los intereses empresariales en la conformación del currículo, que refuerza el papel de la educación en la reproducción social de los rasgos degradantes: individualismo, especialización reduccionista y excluyente, pasividad política, competitividad, consumismo alienante y vulnerabilidad a la manipulación mediática. La sintonía estriba en favorecer los intereses de lucro, dado que tales rasgos son condición necesaria de su dominación.

- La tercera tiene hondas raíces históricas, porque la educación pasiva, bajo diferentes ropajes, ha constreñido e inhibido secularmente (al soslayar la crítica) el despliegue y el desarrollo de las potencias cognoscitivas, perpetuando la pasividad ante el conocimiento. Esto ha significado la forma de control de conciencias y cuerpos menos ostensible, cegándolos a la dominación de los intereses en turno. Ahora mismo es lo que subyace a la indiferencia y la insensibilidad ante la ruina de una civilización que a todos arrastra y que destruye el planeta

En la educación pasiva, la crítica, como lógica organizativa metódica de la cognición, está ausente, minimizada o desvirtuada, como revela la idea de conocimiento que promueve e impulsa (consumo y acumulación de información). Solo hasta los niveles superiores la crítica, en especial en los programas de formación de investigadores, hace una aparición restringida a lo metódico instrumental de las indagaciones factuales, soslayando el universo de las ideas donde moran las lógicas, los ismos, los prejuicios, los dogmas, las creencias, los saberes establecidos o las prácticas predominantes que condicionan las formas sociales de pensar, percibir, indagar, interpretar, actuar u organizarse (al respecto, el empirismo reduccionista y la especialización excluyente son emblemas del quehacer científico actual). En suma, las ideas y prácticas de la educación pasiva, incluidos los niveles superiores y de posgrado, operan, al igual que las que predominan en los otros ámbitos de actividad, como agentes de la dominación (de gran efectividad, pues no se perciben como tales) de los intereses de lucro, al afianzarlos, favorecerlos o encubrirlos. Consecuencia de lo anterior es que el proceso educativo preponderante está imposibilitado - aunque se lo proponga - para cumplir los ideales formativos de forjador de las fuerzas liberadoras y de superación de la condición humana en lo espiritual, moral, intelectual y convivencial (donde lo material es un supuesto y, con frecuencia, un señuelo de superación), y en la responsabilidad por el cuidado del ecosistema planetario.

En cuanto a la investigación educativa, también se desarrolla, con raras excepciones, bajo la mirada restrictiva de la educación pasiva (con muchas variantes y matices); de ahí que los supuestos progresos educativos que aporta la investigación suelan ser «llover sobre mojado". El progreso de la educación no tiene que 
ver con perfeccionar la educación pasiva cómplice y soporte de la degradación. Requiere otra base epistemológica que posibilite un cambio de enfoque de la formación de profesionales progresivamente conscientes del mundo degradado y degradante que habitamos, y con aptitudes cognitivas que los lleven a integrar colectivos que desarrollen su propio quehacer en perspectiva a la búsqueda de otro mundo posible y deseable. (Todo esto es aplicable a la educación médica).

\section{La educación participativa}

La teoría de la educación participativa no resultó de un descubrimiento, sino de la crítica de la educación pasiva (sus bases epistemológicas). Su desarrollo no fue un fenómeno de todo o nada, sino de aproximaciones sucesivas al nuevo objeto, que van revelando lo que permanecía subestimado, profundizando cuestionamientos que se quedaron cortos o restringidos, 0 redondeando ideas o conceptos más penetrantes 0 acciones más efectivas y heurísticas. Tuvo sus inicios hace tres décadas, a propósito de especificar los lineamientos de este tipo de educación ${ }^{14}$, basada en la idea de conocimiento como elaboración propia de los educandos a partir de la reflexión de su experiencia vital, lo que es diametralmente distinto de lo que está implícito en la educación pasiva.

Según esta teoría, la posibilidad de encauzar a los protagonistas del proceso educativo hacia la participación radica en la configuración efectiva de ambientes propicios para la crítica profunda y creativa, y la elaboración de un conocimiento penetrante. Esto implica formas inéditas de articular y alinear las materias del currículo, de priorizar los temas a tratar, de estudiar, de organizar las actividades, de los métodos pedagógicos, del tipo de tareas o de los modos de proceder de los diversos participantes. Lo decisivo para lograr esos ambientes es contagiar entusiasmo a los educandos por entenderse a sí mismos y sus respectivos contextos percibidos. Tal contagio se inicia con la reflexión introspectiva de su experiencia vital al concienciar preocupaciones, desasosiegos, dudas, deseos, preferencias, inclinaciones, conflictos, frustraciones, problemas o aspiraciones dependientes de su momento etario y de sus circunstancias peculiares, que los lleva a entender, satisfacer, superar, proyectar o serenarse, según el caso. Es decir, cuando indagar sobre el sí mismo y el contexto se experimenta como interesante, provechoso, fructífero o gratificante para un mejor vivir, el contagio ha tenido lugar. Lo destacable de la educación participativa es que posibilita la conformación de ambientes propicios para la crítica y la elaboración del conocimiento (con énfasis en la educación médica) $)^{7}$ :

- La condición sine qua non de participación en el conocimiento es que la reflexión de la experiencia vital tome su lugar como autorreferente y motivador de la búsqueda cognitiva.

- Como la experiencia vital es punto de encuentro del sí mismo y del contexto (interacciones del sujeto con los objetos significativos de su entorno peculiar), la reflexión erige a ambos como los objetos de conocimiento central de las experiencias de aprendizaje que poco a poco se extienden, conforme la crítica profunda y creativa favorece un conocimiento penetrante $y$ liberador, a quiénes somos y dónde estamos.

- En el proceso de elaboración del propio conocimiento, lo primario es el aprendizaje con sentido para la experiencia vital, lo que ocurre cuando los materiales de estudio seleccionados y secuenciados ex profeso logran la sintonía con los intereses cognitivos del momento etario y circunstancial de los educandos. Es decir, cuando lo estudiado concierne, esclarece, responde, tranquiliza o da salida a lo que más inquieta, conflictúa, conmueve, atrae o entusiasma al sujeto, tiene lugar el aprendizaje con sentido, que deja huella porque está vinculado con sus entrañas afectivas.

- El acto de estudiar es, por encima de todo, ejercer la crítica al concienciar y opinar sobre el texto, desde un incipiente «me gusta o no» hasta proponer puntos de vista alternativos, pasando por enjuiciar lo bien 0 mal planteado, lo interesante o insulso, lo esclarecedor o confuso, lo fuerte o débil, los silencios significativos o externar coincidencias y discrepancias. Cuando se conjuntan sentido y crítica, ciertos fragmentos, aspectos o ideas de lo estudiado se interiorizan e integran (tamizados y moldeados por la crítica), y entran a formar parte del sí mismo (puntos de vista propios). Poco que ver con el recuerdo efímero de información ajena.

- La crítica es factible desde etapas tempranas porque, desde el principio, el sentido de lo estudiado suscita interés y avidez, y el ambiente incita a opinar, valorar y argumentar al respecto, que son medios de intercambio de puntos de vista diversos que enriquecen la discusión en el aula.

- La relación entre teoría y práctica se invierte: la teoría enriquece, a posteriori, la reflexión de la experiencia vital en sus afanes por penetrar el sí mismo y el contexto; las vivencias prácticas reflexionadas cuestionan 
(critican) la teoría al reconocer sus limitaciones o insuficiencias, para dar cuenta de lo que pretende.

- El meollo de la labor magisterial es incitar en el alumnado la reflexión introspectiva de su experiencia vital, a fin de contagiarle entusiasmo por entenderse y entender el mundo que le toca vivir, que es condición para promover y encauzar el ejercicio efectivo de la crítica en la elaboración de su conocimiento. Esto supone, por parte de las y los docentes, haber recorrido cierto trecho en su aventura de elaboración del conocimiento ejerciendo la crítica, porque nadie puede «contagiar» a otros lo que «no padece» o aquello de lo que «no es portador».

- El papel del discente incitado y contagiado es desarrollar sus potencias cognoscitivas mediante la crítica al protagonizar el conocimiento de sí mismo y su contexto, que se diferencian en dos tipos de aptitudes interdependientes:

a) Metodológicas: lectura crítica de textos teóricos y de informes de investigaciones factuales, realización de investigaciones teóricas (universo de las ideas) y factuales (mundo de los hechos).

b) Prácticas: la aptitud docente y la aptitud clínica ${ }^{5}$.

- La evaluación es el medio de seguimiento y valoración de los alumnos en el desarrollo de aptitudes y de sus progresos en la crítica, donde las insuficiencias o desviaciones son, en principio, atribuibles al sistema educativo. También es recurso valioso para motivar y orientar los esfuerzos de superación individuales y colectivos.

- La especialización incluyente es la aspiración formativa. Cuando los referentes de la cognición a lo largo del proceso son el sí mismo y el contexto percibido, ciertos componentes o facetas de las disciplinas estudiadas, moldeadas por la crítica profunda y creativa, se van conjuntando en una nueva matriz organizativa: los puntos de vista propios sobre ciertos problemas en forma de perspectivas integradoras, donde los límites arbitrarios entre los saberes tienden a difuminarse para dar lugar a miradas transdisciplinarias ${ }^{4}$. En la especialización incluyente, el especialista, provisto de marcos interpretativos amplios e integradores, relativiza su actividad profesional en función de su interdependencia con otras, y en colectivo con sus pares van descifrando el orden imperante e ideando alternativas en el pensar, el actuar y el organizar a fin de sobreponerse a los rasgos degradantes y emprenderla hacia otro mundo posible.

- El desiderátum es el conocimiento penetrante y liberador, que cristaliza en colectivos con potencias cognoscitivas inusitadas pertrechadas con la crítica profunda y creativa a manera de fuerzas sociales portadoras de proyectos vitales altruistas, empeñadas en la lucha interminable por la dignificación de la vida: superación espiritual, intelectual, moral y convivencial de la condición humana hacia otro mundo posible (sociedades inclusivas, pluralistas, igualitarias, justas, solidarias y cuidadosas del ecosistema planetario).

Deriva de lo dicho que, según la educación participativa, el proceso formativo es un continuo (no lineal) de elaboración cognitiva de por vida que puede iniciarse desde temprana edad. Es decir, contagiar entusiasmo por entender quiénes somos y dónde estamos, orientar la búsqueda cognitiva e incitar y encauzar el ejercicio de la crítica es, toda proporción guardada y mutatis mutandis, el eje invariante del proceso que toma expresiones diferentes conforme la crítica se hace más profunda, el conocimiento más penetrante y varían los intereses cognitivos del alumnado según su edad $^{\mathrm{b}}$. El meollo de la participación es el dominio progresivo de la crítica en la cognición penetrante y liberadora del sí mismo y del contexto. Los obstáculos para la difusión social de esta educación son múltiples, derivados de su discordancia con los intereses dominantes, manifiesta en el campo educativo por la indiferencia o el rechazo de las cúpulas seguras de sus certezas. De la factibilidad de la educación participativa son elocuentes las experiencias fructíferas con grupos de edad extrema: alumnos de primaria temprana y docentes de educación superior ${ }^{15,16}$.

\section{Responsabilidades éticas}

Protección de personas y animales. El autor declara que para esta investigación no se han realizado experimentos en seres humanos ni en animales.

Confidencialidad de los datos. El autor declara que han seguido los protocolos de su centro de trabajo sobre la publicación de datos de pacientes.

Derecho a la privacidad y consentimiento informado. El autor declara que en este artículo no aparecen datos de pacientes.

b La educación pasiva es, según esta idea, artificiosa y arbitraria al fijar los distintos niveles educativos basándose en supuestas complejidades cualitativamente diferentes de las habilidades cognitivas a desarrollar en cada nivel (en realidad, la principal habilidad cognitiva que se promueve a todo lo largo de la educación formal es jla memoria!), porque subestima -por su miopía epistemológica- las posibilidades cognoscitivas y los alcances cognitivos potenciales de niños y jóvenes que suelen permanecer latentes mientras no sean incitados $y$ encauzados en el ejercicio de la crítica. 


\section{Conflicto de intereses}

El autor declara no tener conflicto de intereses.

\section{Financiamiento}

Ninguno.

\section{Bibliografía}

1. Viniegra-Velázquez L. El orden cultural, la enfermedad y el cuidado de la salud. Bol Med Hosp Infant Mex. 2017;74:397-406.

2. Navarro V. Quién domina la gobernanza de la Eurozona. En: Ataque a la democracia y al bienestar. Crítica al pensamiento económico dominante. Barcelona: Anagrama; 2015. p. 53-60.

3. Navarro V. El ataque a la Europa Social. En: Ataque a la democracia y al bienestar. Crítica al pensamiento económico dominante. Barcelona: Anagrama; 2015. p. 61-73

4. Viniegra-Velázquez L. La educación en nuestro tiempo: ¿competencia o aptitud? El caso de la medicina. Parte I. Bol Med Hosp Infant Mex. 2017:74:164-72.

5. Viniegra-Velázquez L. Aptitudes y educación médica en tiempos oscuros. Parte I. Inv Ed Med. 2017;6:272-80.

6. Viniegra-Velázquez L. Un replanteamiento de la función de la escuela Educación y crítica. El proceso de elaboración del conocimiento. México: Paidós Educador; 2002. p. 113-41.
7. Viniegra-Velázquez L. Caracterización de las dos perspectivas epistemológicas de la educación. La educación y la crítica del conocimiento. Una perspectiva transdisciplinaria para entender la subjetividad y sus posibilidades cognitivas. México: Invipress-Hospital Infantil de México; 2015. p. 187-98.

8. Argüelles A, Gonczi A. Educación y capacitación basada en normas de competencia: una perspectiva internacional. México: Limusa; 2001.

9. Posada AR. Formación superior basada en competencias. Interdisciplinariedad y trabajo autónomo del estudiante. Revista Iberoamericana de Educación. 2004;34:1-33.

10. Farfán Flores P, Pérez García I, González Gutiérrez M, Huerta Amezola J, López Ortega A, Crocker Sagástume R, et al. Competencias profesionales integradas. Una propuesta para la evaluación y reestructuración curricular en la educación superior. México: Universidad de Guadalajara; 2010.

11. López Ortega A, Farfán Flores P, Ramírez Anguiano V. Aprendizaje situado. Un modelo para la enseñanza y el aprendizaje en las especialidades médicas. México: Hospital Civil de Guadalajara; 2013.

12. Frenk J, Chen L, Bhutta Z, Cohen J, Crisp N, Evans T, et al. Health professional for a new century: transforming education to strengthen health systems an independent world. Lancet. 2010;376:1923-58.

13. Viniegra-Velázquez L. El camino de la crítica y la educación. Rev Invest Clin. 1996;48:139-58.

14. Viniegra-Velázquez L. Los intereses académicos en la educación médica. Rev Invest Clin. 1987;39:281-90.

15. Aguilar-Mejía E, Viniegra-Velázquez L. Atando teoría y práctica en la labor docente. México: Paidós Educador; 2003.

16. Viniegra-Velázquez L, Aguilar E. Hacia otra concepción del currículo. Un camino alternativo para la formación de docentes-investigadores. México: IMSS; 2003. p. 63-172. 